\title{
AUV Application for Inspection of Underwater Communications
}

\author{
Alexander Inzartsev and Alexander Pavin \\ Institute of Marine Technology Problems (IMTP FEB RAS) \\ For Eastern Branch of the Russian Academy of Sciences \\ Russia
}

\section{Introduction}

Regular inspection of underwater communications (pipelines and cables) is actual problem of modern oil and gas industry. Specially equipped vessels, towed underwater devices and remote operated vehicles / $\mathrm{ROV} /$ are applied for these purposes as usually, but quality of acquired data does not always allow revealing emergencies at the proper time. "Spot" inspections by ROVs give difficultly comparable data (Baker, 1991; Murray, 1991). The perspective solution of the problem is autonomous underwater vehicles / AUV/ application as "the intellectual carrier" of research equipment (Evans et al., 2003; Kojima et al., 1997).

According (Ageev, 2005) the main goals of pipeline and cables inspection are:

1. more accurate position determination (searching and tracking);

2. pipe sagging and freespan detection and measurement;

3. terrain survey on each side of communication by means of high frequency side scan sonar /HF SSS/ and detection of extraneous objects;

4. detection of damages;

5. leakage detection of transported substances (for pipelines).

The pipeline and cable inspection by means of AUV includes two stages: preliminary (communication search and detection) and the main (motion along the communication with carrying out of necessary measurements, i.e. tracking). Exact mutual orientation of AUV and inspected object is required in real time during the tracking stage.

To solve inspection tasks AUV should be equipped with reliable detection systems for inspected object recognition. Video, electromagnetic and echo-sounder data can be used for these purposes. Each of these devices demonstrates optimal results for certain classes of objects in appropriate conditions. For example, metal pipelines have the significant sizes and can be detected by all listed above devices. While underwater cables have a small diameter, because of this applicability of acoustic methods is limited (Petillot et al., 2002). Process of communications search and detection is complicated, as a rule, with a poor visibility of the given objects (strewed with a ground, silted or covered by underwater flora and fauna).

Experiments with the use of AUV for inspection of underwater communications have been carried out for a long time. Usually only one instrument, which AUV is equipped with, is used for object detection.

Source: Underwater Vehicles, Book edited by: Alexander V. Inzartsev,

ISBN 978-953-7619-49-7, pp. 582, December 2008, I-Tech, Vienna, Austria 
The first experiments with detection and inspection of metal cables were carried out with the use of AUV "Aqua Explorer 2" (Asai at al., 2000). The AUV was equipped with two external magnetometers which allowed to find out metal cables. However the devices allowed to find out only active cables (i.e. cables with electric current). Devices did not find out cables where there was not electric current for any reasons (for example, because of breakage). Moreover AUV had significant transverse dimensions because of magnetometers installation on pylons.

The basic possibility of video camera use for automatic cables detection and tracking was shown in (Matsumoto \& Ito, 1995; Ortiz at al., 2000). And the firsts practical results were obtained with the use of semi-AUV TSL (Scherbatyuk at al., 2000) and ROVs Ventana and Tiburon (Kogan at al., 2006).

The experiments of pipelines tracking with the use of multi-beam echo sounder were carried out on the base of AUV AUTOTRACKER (Petillot et al., 2002) and revealed good enough results. However the used facilities allowed to detect the inspected object only at strict mutual orientation of AUV and the pipeline.

Detection reliability of lengthy metallic objects (cables and pipelines) can be considerably increased by means of synchronous data processing of the all recognition devices. In other words, it is necessary to equip AUV with a plenty of detection systems which work on the basis of different physical principles. For the sake of reliability the information from the different sources is combined into "environment model" and processed jointly. "Environment model" is updated on the basis of new data and can be used for subsequent AUV motion planning. The questions of object recognition, "environment model" structure and AUV behavior during inspection are considered in this paper.

\section{Pipeline \& cable recognition systems}

Further we assume that AUV is equipped with several diverse recognition systems, capable to work simultaneously. For inspected object position estimation all data from recognition subsystems should be in uniform format. It is supposed, that each object identification subsystem $n(n=1 \ldots N, N$ - number of subsystems) periodically gives out the following data:

- vector of position and direction of the inspected object (in absolute coordinate system) $\boldsymbol{r}_{t}^{<n>}=\left[X_{t}^{<n>}, Y_{t}^{<n>}, \Phi_{t}^{<n>}\right]^{\mathrm{T}}$.

- estimation of object existence probability $p_{t}^{<n>}$.

It is also supposed that AUV is equipped with onboard navigation system which is necessary for recognition subsystems data integration. It gives current AUV coordinates in the next format: $\boldsymbol{r}_{t}^{\mathrm{AUV}}=\left[X_{t}^{\mathrm{AUV}}, Y_{t}^{\mathrm{AUV}}, \Phi_{t}{ }^{\mathrm{AUV}}\right]^{\mathrm{T}}$. During inspection vehicle moves on a relatively small distance over the sea bottom, therefore a Doppler velocity log /DVL/ can be used for AUV position determination. The best models of modern DVL provide measurement accuracy of speed at a level 1-2 mm/s. The accumulating position error in this case does not exceed 10 meters per hour that is quite allowable for maintenance of a positive control for cable tracking.

For the sake of definiteness we shall assume, that AUV is equipped with the following systems:

- $\quad$ video imaging complex /VIC/;

- $\quad$ electromagnetic searcher /EMS/;

- multi-beam echo-sounder system /MB ESS/.

Let's consider operation peculiarities of these systems. 


\subsection{Video imaging complex for cable and thin pipeline recognition}

Some communications (e.g. cables and pipelines with small diameter) can be detected on photo and video images as a pair of parallel lengthy lines. The basic function of VIC is data collection about inspected object and its identification (detection) on a seabed. Object identification consists of search of the longest straight line presented on the image. Hough transformation is used as the basic mathematical tool (Scherbatyuk, 1998). The recognition system output includes (fig. 1):

1. direction of the recognized object $\mathrm{a}_{t}<\mathrm{VIC}>$;

2. distance from video camera to the object $\rho_{t}<\mathrm{VIC}>$;

3. length of a visible part of the object $l_{t}^{<\mathrm{VIC}>}$.

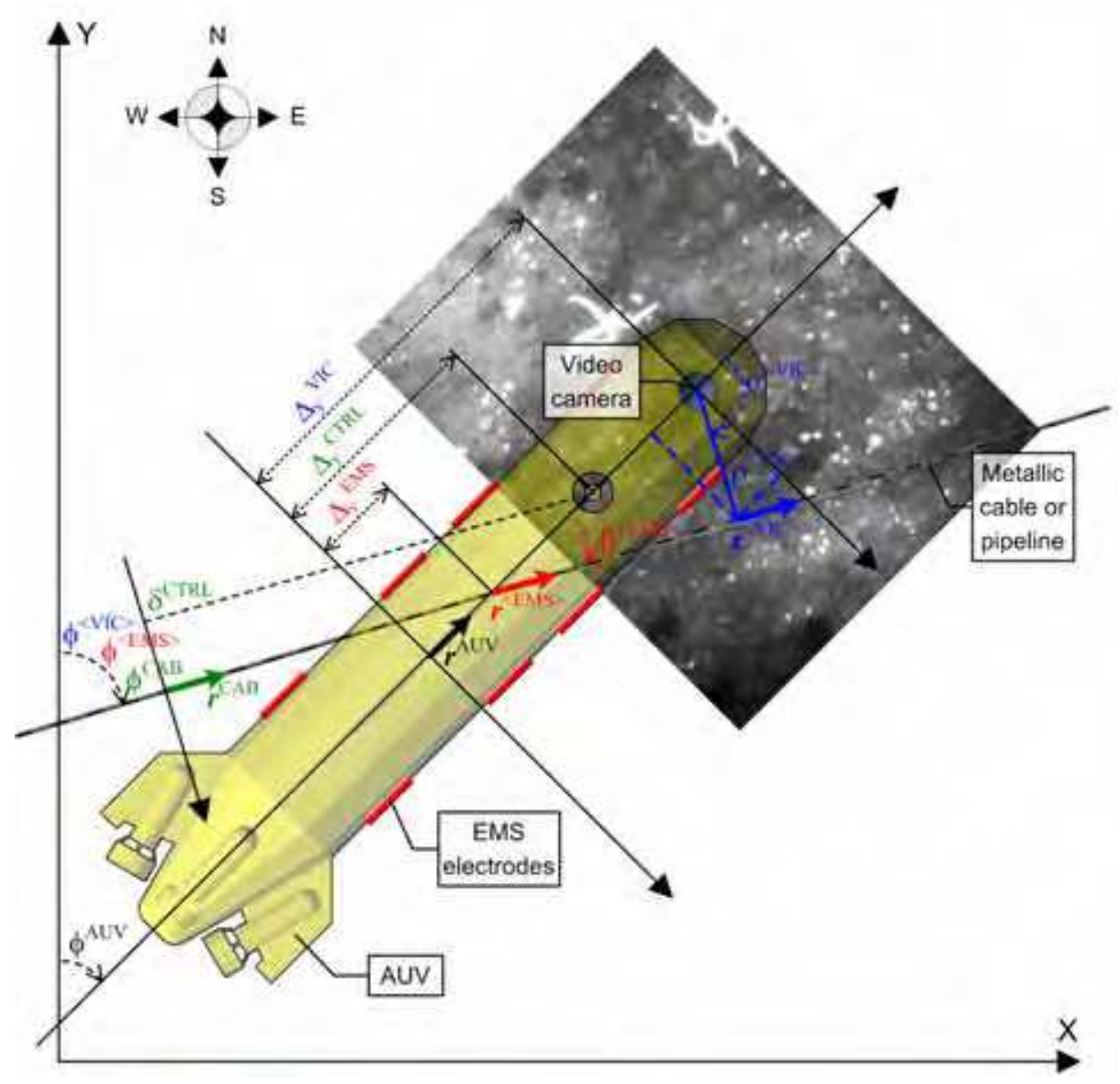

Fig. 1. AUV coordinate systems and devices arrangement

The position-direction vector $\boldsymbol{n}<\mathrm{VIC}>=\left[X_{t<\mathrm{VIC}>}, Y_{k<\mathrm{VIC}>}, \Phi_{t<\mathrm{VIC}>}\right]_{\mathrm{T}}$ of recognized object in absolute coordinate system for a camera directed downwards perpendicularly to AUV shape is calculated as follows (neglecting AUV pitch and roll which during object inspection do not exceed several degrees): 


$$
\begin{gathered}
\boldsymbol{r}_{t}^{<\mathrm{VIC}>}=\left[\begin{array}{c}
\left.\left[\begin{array}{c}
X_{t}^{\mathrm{AUV}} \\
Y_{t}^{\mathrm{AUV}}
\end{array}\right]+\mathbf{G}\left(\Phi_{t}^{\mathrm{AUV}}\right) \cdot\left(\left[\begin{array}{c}
\Delta_{x}^{\mathrm{VIC}} \\
\Delta_{y}^{\mathrm{VIC}}
\end{array}\right]+\left[\begin{array}{c}
x_{t}^{\prime<\mathrm{VIC}>} \\
y_{t}^{\prime<\mathrm{VIC}>}
\end{array}\right]\right)\right] \\
\Phi_{t}^{\mathrm{AUV}}+\alpha_{t}^{<\mathrm{VIC}>}-\operatorname{sign}\left(\alpha_{t}^{<\mathrm{VIC}>}\right) \cdot 90^{0}
\end{array}\right] \\
x_{t}^{\prime<\mathrm{VIC}>}=\rho_{t}^{<\mathrm{VIC}>} \cdot \sin \left(\alpha_{t}^{<\mathrm{VIC}>}\right) \\
y_{t}^{\prime<\mathrm{VIC}>}=\rho_{t}^{<\mathrm{VIC}>} \cdot \cos \left(\alpha_{t}^{<\mathrm{VIC}>}\right) \\
\mathbf{G}(\varphi)=\left[\begin{array}{cc}
\cos (\varphi) & \sin (\varphi) \\
-\sin (\varphi) & \cos (\varphi)
\end{array}\right]
\end{gathered}
$$

Where: $x_{t}^{\prime}<\mathrm{VIC}>, y_{t}^{\prime}<\mathrm{VIC}>-$ object position on the video camera image; $\Delta_{x} \mathrm{VIC}, \Delta_{y} \mathrm{VIC}-$ onboard camera position; $\mathbf{G}(\varphi)$ - turn-matrix of coordinate system to an angle $\varphi$.

It is necessary to note that video recognition system does not guarantee reliable results due to noisy objects can be present on images (starfishes, alga, stones, sea garbage and so on) or inspected object can be invisible (buried or hidden by other objects). The probability $p_{t<\mathrm{VIC}>}$ of correct recognition depends on identified length and direction of the line on the image. If line is long and lies down in appropriate direction then probability is high. Video imaging complex contacts and cable existence probability function during object inspection mission are shown on fig. 2.
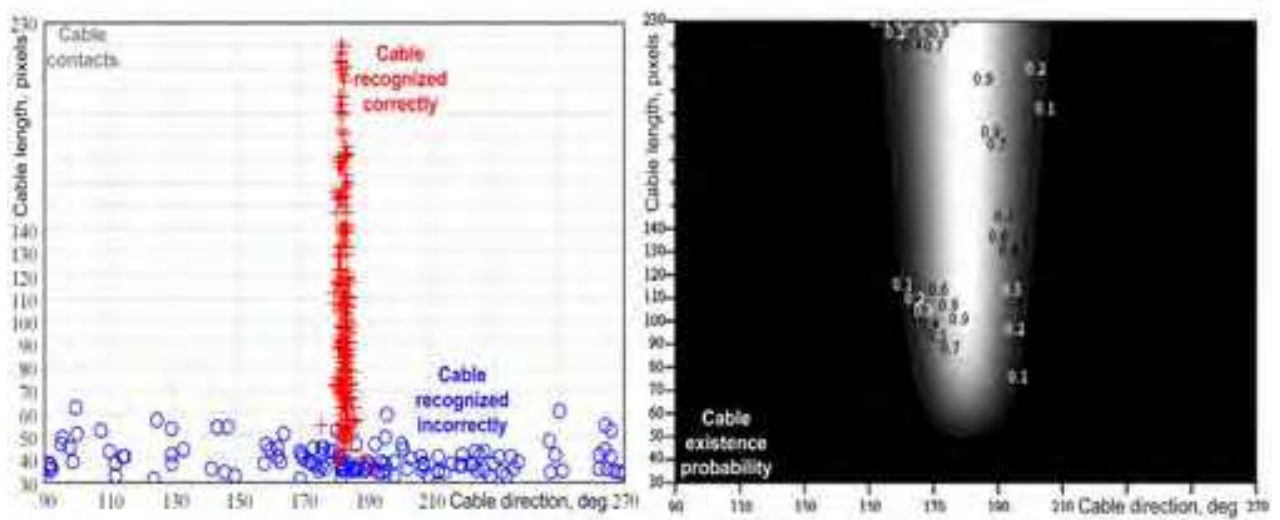

Fig. 2. VIC contacts filtration example: detected contacts (left image), existence probability (right image)

\subsection{Electromagnetic searcher for metallic cable and pipeline recognition}

Metallic communications (e.g. cables and pipelines) can be detected on the basis of electromagnetic methods.

EMS operation is based on electromagnetic field excitation in a water column and environment reaction measurement on this field (Kukarskih \& Pavin, 2008). Electromagnetic Searcher (fig. 3) consists of three pairs of transmitting $A_{0}, A_{1}, A_{2}$ and receiving $B_{0}, B_{1}, B_{2}$ dipole antennas (TX- and RX- antennas) formed by corresponding electrodes $A_{1}{ }^{\prime} A_{2}{ }^{\prime}-A_{1}{ }^{\prime \prime} A_{2}{ }^{\prime \prime}$, $A_{1}^{\prime}-A_{1}^{\prime \prime}, A_{2}^{\prime}-A_{2}^{\prime \prime}$ and $B_{1}^{\prime} B_{2}^{\prime}-B_{1}^{\prime \prime} B_{2}^{\prime \prime}, B_{1}^{\prime}-B_{1}^{\prime \prime}, B_{2}^{\prime}-B_{2}^{\prime \prime}$ (electrodes of antennas $A_{0}$ and $B_{0}$ are paired). 
TX-dipole antennas directed at a sharp angles $\mathrm{a}_{0}, \mathrm{a}_{1}, \mathrm{a}_{2}$ with AUV longitudinal axis. Angles of RX-antennas $\left(\beta_{0}, \beta_{1}, \beta_{2}\right)$ fitted so that transmitting electromagnetic field do not influence to corresponding RX-dipoles (mutual TX- and RX- antennas angles differ from $90^{\circ}$ because of the field distortions by AUV shape). Such approach allows metallic object detection at any attack angle of the vehicle and the object.

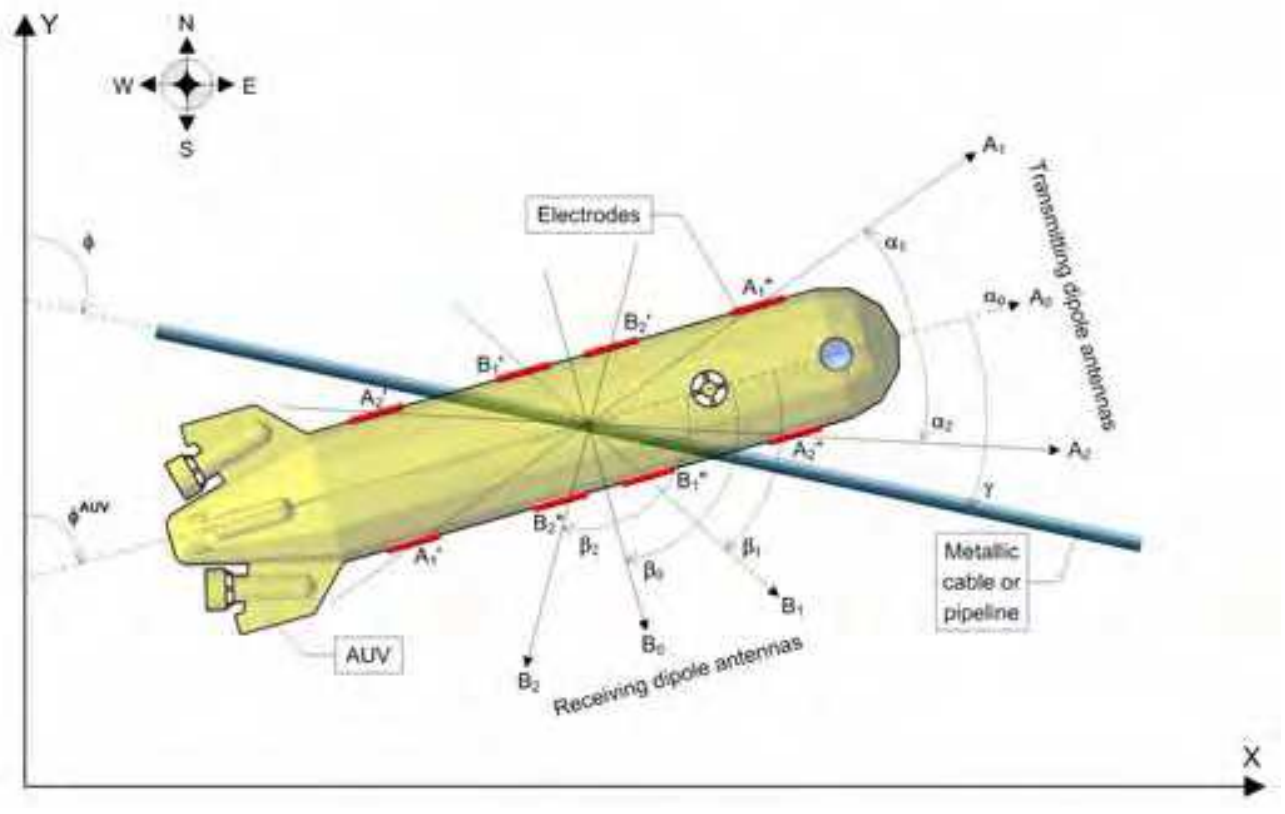

Fig. 3. Electrodes arrangement of EMS

Thus, alternately excite dipoles $A_{n}(n=0,1,2)$ the current $I_{n}$ will be induced in the object:

$$
\begin{gathered}
I_{n}=I_{n} A_{n} \cdot R^{A} n(\rho) \cdot \cos \left(\mathrm{\gamma}-\mathrm{a}_{\mathrm{n}}\right) \\
R^{A} n(\rho) \approx K^{A}{ }_{n} \cdot \rho^{-3}
\end{gathered}
$$

Where: $\gamma$ - angle between AUV longitudinal axis and lengthy metallic object; $\rho$ - distance from the center of electrode system up to object; $R^{A} n(\rho)$ - function of dependence of the current induced in a metallic object (by antenna $A_{n}$ ) from distance up to it; $I_{n}{ }_{n}$ - the current in dipole $A_{n} ; K^{A}$ - the constant coefficient dependent on AUV constructive properties, antenna $A_{n}$ and electromagnetic properties of metallic object.

RX-antenna $B_{n}$ measure potential difference $U_{n}$ during transmitting of corresponding antenna $A_{n}$. Electrical field lines (induced in a metallic object) are directed along the lengthy object, because of this the potential difference $U_{n}$ on antenna $B_{n}$ depend on the following laws:

$$
\begin{gathered}
U_{n}=I_{n} \cdot R_{n}^{B_{n}}(\rho) \cdot \cos \left(\mathrm{\gamma}-\beta_{\mathrm{n}}\right) \\
R_{n}^{B_{n}}(\rho) \approx K^{B_{n}} \cdot \rho^{-2}
\end{gathered}
$$


Where: $R^{B} n(\rho)$ - potential difference function for antenna $B_{n}$ (depend of distance from object); $K^{B_{n}}$ - the constant coefficient characterizes antenna $B_{n}$.

Metallic object detection problem consist of calculation next two values: $\varphi$ - object direction angle (fig. 3) and $v$ - object vicinity to AUV (object existence probability assessment near the underwater vehicle). Value $\varphi$ obtained by adding AUV heading (in absolute coordinate system) $\varphi^{\mathrm{AUV}}$ and AUV-object mutual angle $\gamma: \varphi=\varphi^{\mathrm{AUV}}+\gamma$. Using (5) \& (7) and replace $R_{n}(\rho)=I^{A}{ }_{n} \cdot R^{A} n(\rho) \cdot R^{B}{ }_{n}(\rho)(n=0,1,2)$ the next system of equations can be obtained for synchronous detected potential difference $U_{n}$ :

$$
\left\{\begin{array}{l}
U_{n}=R_{n}(\rho) \cdot \cos \left(\gamma-\alpha_{n}\right) \cdot \cos \left(\gamma-\beta_{n}\right) \\
R_{n}(\rho)>0 \\
n=0,1,2
\end{array}\right.
$$

Using equation (9) with $n=1,2$ and the fact that $R_{1}(\rho) \approx R_{2}(\rho) \approx R(\rho)$ (because $A_{1}-B_{1}$ and $A_{2}-B_{2}$ is symmetrical, see fig. 3 ) the next solving relatively $\gamma$ can be obtained:

$$
\begin{gathered}
a \cdot \tan ^{2} \gamma+b \cdot \tan \gamma+c=0 \\
\gamma_{12}=\arctan \frac{-b \pm \sqrt{b^{2}-4 \cdot a \cdot c}}{2 \cdot a}
\end{gathered}
$$

Where: $a=U_{1} \cdot\left(\sin \alpha_{2} \cdot \sin \beta_{2}\right)-U_{2} \cdot\left(\sin \alpha_{1} \cdot \sin \beta_{1}\right), b=U_{1} \cdot\left(\sin \alpha_{2} \cdot \cos \beta_{2}+\cos \alpha_{2} \cdot \sin \beta_{2}\right)$ $-U_{2} \cdot\left(\sin \alpha_{1} \cdot \cos \beta_{1}+\cos \alpha_{1} \cdot \sin \beta_{1}\right), c=U_{1} \cdot\left(\cos \alpha_{2} \cdot \cos \beta_{2}\right)-U_{2} \cdot\left(\cos \alpha_{1} \cdot \cos \beta_{1}\right)$.

The next situations can be during calculating (11):

1. Equation (11) haven't real roots. It means that lengthy metallic object does not exist near the $\operatorname{AUV}(v=0)$.

2. Equation (11) have one or two real roots. The $\operatorname{root} R_{n}(\rho)>0(n=0,1,2)$ will be chosen. Object vicinity v can be estimated basing on $R_{n}(\rho)$ values calculated from (9). Each $R_{n}(\rho)$ $(n=0,1,2)$ has maximum value when AUV situated over the metallic object. Besides, sensitivity of each transmitting-receiving electrode system $A_{n}-B_{n}$ depends of angle $\gamma(11)$. Using weighted sum of $R_{n}(\rho)$ with corresponding weights $\left|\cos \left(\gamma-\mathrm{a}_{\mathrm{n}}\right) \cdot \cos \left(\gamma-\beta_{\mathrm{n}}\right)\right|$ for $v$ calculation, the next equation is produced:

$$
\begin{gathered}
v=\frac{\sum_{n=0}^{2}\left|\cos \left(\gamma-\alpha_{n}\right) \cdot \cos \left(\gamma-\beta_{n}\right)\right| \cdot R_{n}(\rho)}{\sum_{n=0}^{2}\left|\cos \left(\gamma-\alpha_{n}\right) \cdot \cos \left(\gamma-\beta_{n}\right)\right|} \\
v=\frac{\sum_{n=0}^{2} U_{n} \cdot \operatorname{sign}\left(\cos \left(\gamma-\alpha_{n}\right) \cdot \cos \left(\gamma-\beta_{n}\right)\right)}{\sum_{n=0}^{2}\left|\cos \left(\gamma-\alpha_{n}\right) \cdot \cos \left(\gamma-\beta_{n}\right)\right|}
\end{gathered}
$$

EMS recognizes orientation of metallic lengthy object during mutually crossing movement. Metallic object position (on EMS data) is the position of electrodes system center at the moment of a potentials maximum on the receiving electrodes. Thus, vector of absolute coordinates may be calculated as follows: 


$$
\left.\mathbf{r}_{t}^{<\mathrm{EMS}>}=\left[\begin{array}{c}
X_{t}^{\mathrm{AUV}} \\
Y_{t}^{\mathrm{AUV}}
\end{array}\right]+\mathbf{G}\left(\Phi_{t}^{\mathrm{AUV}}\right) \cdot\left[\begin{array}{c}
\Delta_{x}^{\mathrm{EMS}} \\
\Delta_{y}^{\mathrm{EMS}}
\end{array}\right]\right]
$$

Where: $\Delta_{x} \mathrm{EMS}, \Delta_{y} \mathrm{EMS}-$ position of electrodes system center; $\beta_{t}^{<\mathrm{EMS}>}-$ mutual AUV-object angle (fig. 1).

EMS operates stably enough (identifies metallic lengthy object and define its crossing angle)

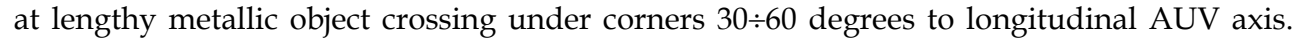
The system operates uncertainly at AUV movement along the object (speed of change of electromagnetic potential is close to zero) and across (emitting electrodes direct too small potential). The estimation of lengthy metallic object existence probability $p_{t<\text { EMS }>}$ can be defined using electromagnetic field potential on the receiving electrodes $v<<$ EMS $>$ (a general

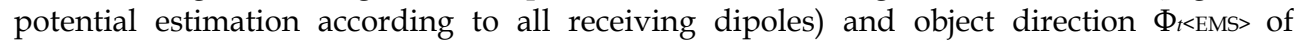
recognized object similarly to VIC contacts filtration (fig. 2).

\subsection{Multi-beam echo-sounder system for pipeline recognition}

It is also supposed, that for pipeline detection AUV uses the echosounder with relatively small number of beams (20-40) (fig. 4).

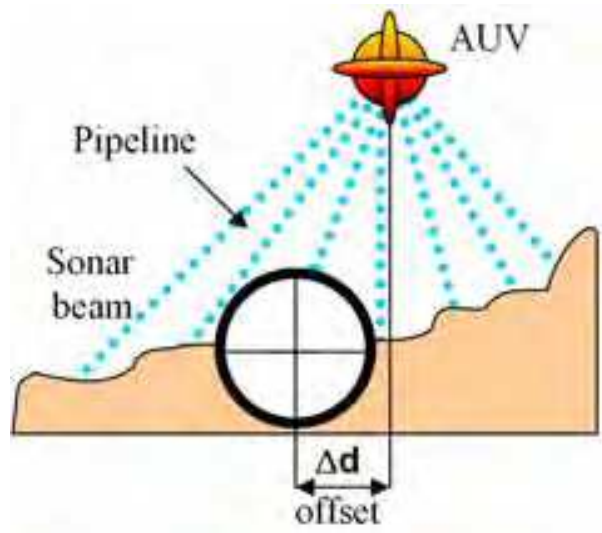

Fig. 4. AUV's sonar beam layout and data gathering process

Fuzzy logic methods were applied for identification of the pipeline (Pavin, 2006). The methods use the known pipeline parameters (diameter of its cross section and approximately known direction of its laying-out). The probability of pipeline correct identification depends on echo sounder and navigation data accuracy. These data compose AUV internal 3D terrain model. The main objective of identification system is an estimation of the pipeline presence probability in this or other place and determination of mutual position (offset) of AUV and the pipeline (fig. 4).

Offered method uses following information for the determination of pipeline exact position:

1. known seabed shape $M_{s, t}$ (it is created from each echo-sounder $\mathbf{s}$ at each moment $t$ when data updating occurred) during time interval $d t$;

2. echo-sounder system accuracy (beam directional diagram angle $\delta_{\mathrm{ES}}$ and distance accuracy $\left.\Delta_{\mathrm{ES}}\right)$; 
3. navigation system accuracy $\delta_{\mathrm{NAV}}$;

4. known radius of the pipeline $R_{\mathrm{PL}}$;

5. $\varphi_{P L}, \Psi_{P L}-$ supposed direction and pipeline inclination;

6. the pipeline is a cylindrical object.

For identification of pipeline location it is enough to identify its top part ("ridge"). In this case the axis of the pipeline settles down below "ridge". The most probable location of pipeline axis is where maximal pipeline existence probabilistic assessment $P$ and coordinates of axes are concentrated along some line. Thus, for determination of the pipeline location it is enough to present the received coordinates as points on the plane $\mathrm{xOz}$ (fig. 5) then it is possible to use fuzzy logic methods of lengthy objects determination based on point's position on the plane.
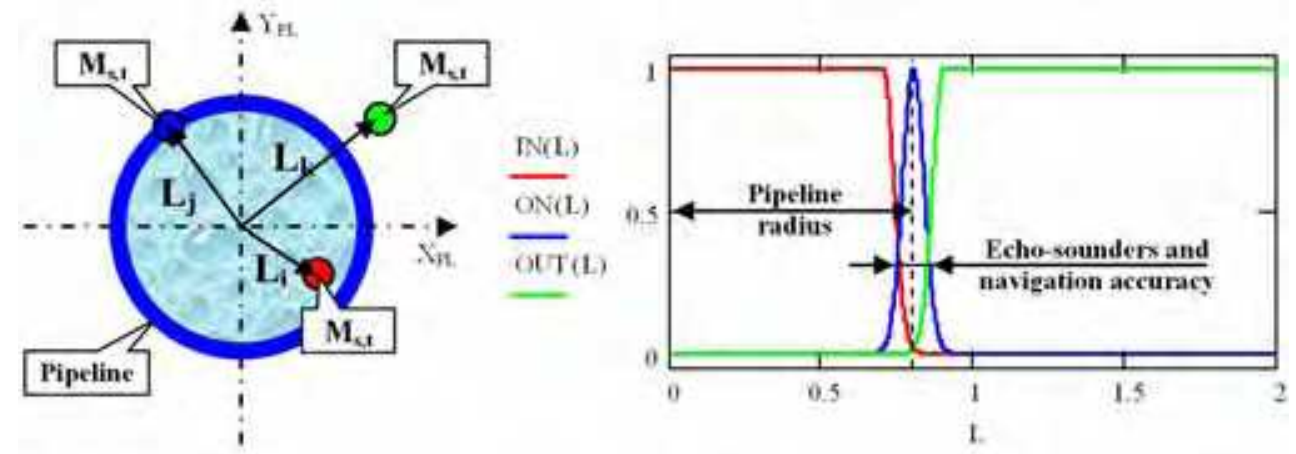

Fig. 5. Map points with pipeline projections (left image) and fuzzy logic values (right image)

The belonging probability of some point to the pipeline surface is appreciated according to following fuzzy rules:

1. The probability of the point belonging to the pipeline surface is higher, than more the neighbor points are "on a surface of the pipeline": If $L=$ "ON the pipe" then $P:=P+P_{\text {true }}$;

2. If some point belongs to the pipeline surface then the neighbor points also lay on its surface, or are outside its borders. Otherwise the existence probability of the pipeline in the given point is reduced: If $L=$ "IN the pipe" then $P:=P-P_{\text {false. }}$.

Values $P_{\text {true }}$ and $P_{\text {false }}$ take from modeling experiments, but supposed that $P_{\text {true }}<P_{\text {false. }}$. Fuzzy values "IN the pipe" and "ON the pipe" depend on echo-sounders accuracy, navigation accuracy and pipeline radius (fig. 5).

\section{Recognition systems data integration}

As was mentioned above, joint operation of various recognition systems is used for detection of objects of different classes. Multi-beam echo-sounders and electromagnetic searchers can be used for objects with the significant sizes of cross section (pipelines). Here EMS can be used only for detection of metallic object presence in AUV vicinity, but not for finding its orientation. EMS and video camera can be used for objects with the small area of cross section (cables and thin pipelines). Let's further consider procedure of data processing and object position finding for these two cases. 
Data integration of Electromagnetic searcher and Video imaging complex are executed for reliable AUV movement during communication lines inspection. Probability $p_{t}^{<n>}$ is a factor of inspection object existence probability in time moment $t$ regarding recognition system $n$. Accumulation of previous contacts can be made (fig. 6):

$$
p_{t}^{<n>\Sigma}=k^{<n>} \cdot p_{t-1}^{<n>\Sigma}+p_{t}^{<n>}
$$

Where: $p_{t}^{<n>\Sigma}$ - total size of contacts by the moment of time $t$ for a subsystem $n ; k^{<n>}-$ factor of attenuation ("forgetting" information of subsystem $n$ ).

The general parameter of object presence $p_{t}{ }^{\Sigma \Sigma}$ according to all recognition systems is defined as the weighed sum of each subsystem estimations $p_{t}^{<n>\Sigma}$ and aprioristic estimation of object presence in the given point $w^{0}\left(X_{t} \mathrm{AUV}, Y_{t}^{\mathrm{AUV}}\right)$. Thus weights $w^{<n>}$ determine a degree of trust to each subsystem:

$$
p_{t}^{\Sigma \Sigma}=\sum_{n}^{N} w^{<n>} \cdot p_{t}^{<n>\Sigma}+w^{0}\left(X_{t}^{A U V}, Y_{t}^{A U V}\right)
$$

Average object direction and position are calculated on the basis of inspection object recognition systems data. The integrated estimation of cable or pipeline position and direction $\boldsymbol{r}_{t}^{\mathrm{CAB}}=\left[X_{t} \mathrm{CAB}, Y_{t} \mathrm{CAB}, \Phi_{t} \mathrm{CAB}\right]^{\mathrm{T}}$ (fig. 6) are similarly calculated, including data $\boldsymbol{r}_{t}^{<n>}=\left[X_{t}^{<n>}, Y_{t}^{<n>}, \Phi_{t}^{<n>}\right]^{\mathrm{T}}$ of each subsystem $n$ and aprioristic information about inspection object location in the given area $\boldsymbol{r}^{0}\left(X_{t}^{\mathrm{AUV}}, Y_{t}^{\mathrm{AUV}}\right)=\left[X^{0}\left(X_{t}^{\mathrm{AUV}}, Y_{t} \mathrm{AUV}\right), Y^{0}\left(X_{t}^{\mathrm{AUV}}, Y_{t}^{\mathrm{AUV}}\right)\right.$, $\left.\Phi^{0}\left(X_{t}^{\mathrm{AUV}}, Y_{t}^{\mathrm{AUV}}\right)\right]^{\mathrm{T}}$ :

$$
\begin{gathered}
\boldsymbol{r}_{t}^{<n>\Sigma}=k^{<n>} \cdot \boldsymbol{r}_{t-1}^{<n>\Sigma}+p_{t}^{<n>} \cdot \boldsymbol{r}_{t}^{<n>} \\
\boldsymbol{r}_{t}^{\mathrm{CAB}}=\frac{1}{p_{t}^{\Sigma \Sigma}} \cdot\left(\sum_{n=1}^{N} w^{<n>} \cdot \boldsymbol{r}_{t}^{<n>\Sigma}+w^{0}\left(X_{t}^{\mathrm{AUV}}, Y_{t}^{\mathrm{AUV}}\right) \cdot \boldsymbol{r}^{0}\left(X_{t}^{\mathrm{AUV}}, Y_{t}^{\mathrm{AUV}}\right)\right)
\end{gathered}
$$

Where: $\boldsymbol{r}_{t}^{<n>\Sigma}=\left[X_{t}^{<n>\Sigma}, Y_{t}^{<n>\Sigma}, \Phi_{t}<n>\Sigma\right]^{\mathrm{T}}$ - temporary variable (a total component of each coordinate by the moment of time $t$ for subsystem $n$ ).

\section{AUV Control during cable or pipeline inspection}

The AUV control during inspection phase supposes: a) time minimization of object search; b) data gathering about the object and surrounding environment (using video and echosounder information). Thus, it is possible to choose the following requirements to AUV movement organization:

1. During initial search stage it is necessary to use the object detection systems possessing the least probability of false operations and to move so that to maximize object detection probability.

2. After detection of any object it is necessary to make sure that the given object is required and proceed to its tracking.

3. AUV tracking trajectory should stretch above the object while there is a steady contact from identification systems.

4. When steady state contact is lost it is necessary to carry out a search trajectory (e.g. "divergent zigzag") to guarantee the return to the object. 

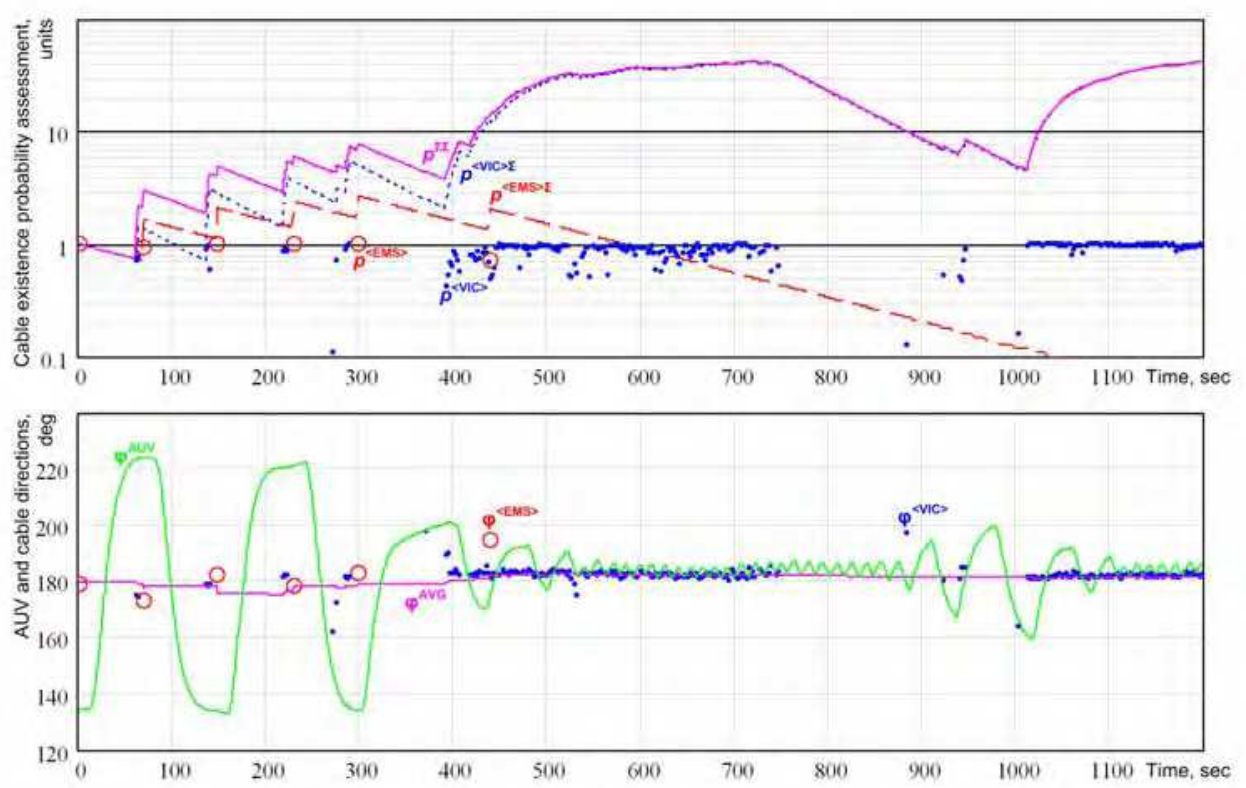

Fig. 6. Example of VIC and EMS data during cable inspection

\subsection{Search the communication line}

So, AUV behavior (Inzartsev \& Pavin, 2006) during pipeline or cable search and detection is similar in many respects and consists of three steps (fig. 7).

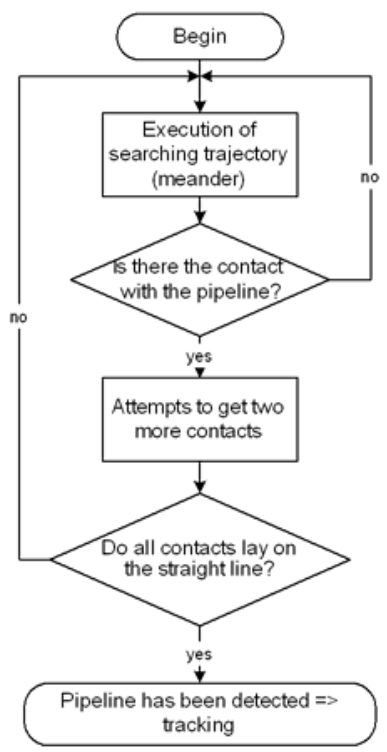

Fig. 7. Flowchart of preliminary phase of inspection 
1. Execution of the search trajectory (meander) in prospective area of the object laying-out as long as crossing with the object looking like the lengthy.

2. Attempt to receive two more confirming contact from the object. For this purpose AUV changes motion direction on the opposite at each point of crossing (contact), i.e. goes by "zigzag". The primary goal of this maneuver is elimination of false contacts and calculation of approximate object direction $\left(\varphi_{\text {mean }}\right)$.

3. If the number of crossing points is three, they lay on the straight line and the direction of this line coincides with the direction of the required object - then object is considered as found out and the stage of its tracking begins. Otherwise contacts are considered as false and the AUV returns to execution of the search trajectory (1).

\subsection{AUV movement control during pipeline or cable tracking}

AUV motion during the pipeline inspection has the features connected with freespan investigation. In the literature the task of main stage is not formalized and usually reduced to the list of the AUV desirable actions. In the paper the following sequence of actions is offered for the implementation of main stage (fig. 8):

1. AUV moves directly above the pipeline, thus:

- leakage detection is fulfilled (the methane sensor is used usually for these purposes);

- the video filming of the pipe surface is carried out;

- $\quad$ SSS imaging is carried out on both sides of the pipeline for detection of extraneous objects;

- $\quad$ pipe saggings and freespans are found out (on the basis of echo sounder data), and their lengths are estimated;

2. in the case of pipe sagging detection AUV moves away from the pipeline with backward motion for performance of SSS imaging;

3. AUV fulfills SSS imaging of sagging from both sides;

4. AUV comes back to the pipeline for continuation of inspection;

5. on completion of communication line inspection, the AUV fulfills backward motion for execution of SSS survey at the offset of 20-25 meters from inspected object.

AUV motion during cable tracking (Inzartsev \& Pavin, 2008) is the same as for pipeline one (excluding item 2). The main goals of inspection can be achieved at AUV motion above the pipeline at height of 1-3 m. Thus, the inspection task is realized as the following algorithm (fig. 8).

The control heading $\Phi_{t}$ CTRL during pipeline or cable tracking can be presented as the sum of the following values: direction of the cable/pipeline $\Phi_{t}{ }^{\mathrm{CAB}}$, the crossing angle $\operatorname{cross}()$ of the inspection object (for "zigzag" trajectory) with corresponding sign Sidet (determining a leftright-side AUV direction movement) and the trajectory stabilization function $\operatorname{stab}()$ above the inspection object (at movement lengthways the inspection object):

$$
\begin{gathered}
\Phi_{t}^{\mathrm{CTRL}}=\Phi_{t}^{\mathrm{CAB}}+\operatorname{Side} e_{t} \cdot \operatorname{cross}\left(p_{t}^{\Sigma \Sigma}\right)-\operatorname{stab}\left(\delta_{t}^{\mathrm{CTRL}}\right) \\
\operatorname{Side}_{t}=\left\{\begin{array}{cc}
-1, & \delta_{t}^{\mathrm{CTRL}}>\operatorname{border}\left(p_{t}^{\Sigma \Sigma}\right) \\
+1, & \delta_{t}^{\mathrm{CTRL}}<-\operatorname{border}\left(p_{t}^{\Sigma \Sigma}\right) \\
\operatorname{Side}_{t-1}, & \left|\delta_{t}^{\mathrm{CTRL}}\right| \leq \operatorname{border}\left(p_{t}^{\Sigma \Sigma}\right)
\end{array}\right.
\end{gathered}
$$




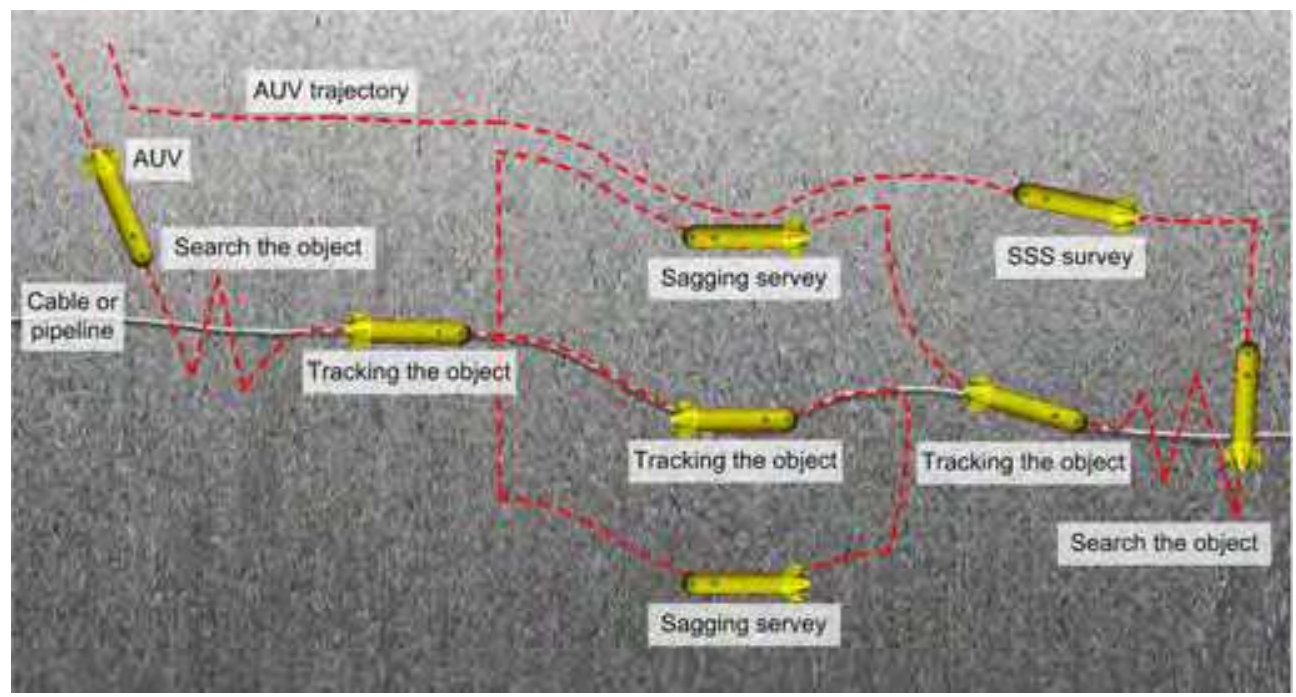

Fig. 8. AUV behavior scheme at inspection of the cable or pipeline

$$
\begin{gathered}
\delta_{t}^{\mathrm{CTRL}}=\left(X_{t}^{\mathrm{CTRL}}-X_{t}^{\mathrm{CAB}}\right) \cdot \cos \left(\Phi_{t}^{\mathrm{CAB}}\right)-\left(Y_{t}^{\mathrm{CTRL}}-Y_{t}^{\mathrm{CAB}}\right) \cdot \sin \left(\Phi_{t}^{\mathrm{CAB}}\right) \\
X_{t}^{\mathrm{CTRL}}=X_{t}^{\mathrm{AUV}}+\Delta_{x}^{\mathrm{CTRL}} \cdot \sin \left(\Phi_{t}^{\mathrm{AUV}}\right) \\
Y_{t}^{\mathrm{CTRL}}=Y_{t}^{\mathrm{AUV}}+\Delta_{y}^{\mathrm{CTRL}} \cdot \cos \left(\Phi_{t}^{\mathrm{AUV}}\right)
\end{gathered}
$$

Where: $\delta_{t}$ CTRL - calculated distance from cable/pipeline to "AUV stabilization point"; border () - size of the inspection border zone. The "AUV stabilization point" is located on the vehicle shape with coordinates: $\Delta_{x}$ CTRL, $\Delta_{y}$ CTRL - in the connected coordinate system and $X_{t}{ }^{\mathrm{CTRL}}, Y_{t} \mathrm{CTRL}^{\mathrm{TR}}$ in absolute coordinate system.

AUV search trajectory is characterized by the crossing angle function $\operatorname{cross}()$ and the trajectory stabilization function border(). Examples of the possible dependences used during AUV field tests are given below:

$$
\begin{gathered}
\operatorname{border}\left(p^{\Sigma \Sigma}\right)=\delta_{\text {min }}^{\text {border }}+\delta_{\text {max }}^{\text {border }} \cdot \exp \left(-K^{\text {border }} \cdot p^{\Sigma \Sigma}\right) \\
\operatorname{cross}\left(p^{\Sigma \Sigma}\right)=\varphi_{\text {min }}^{\text {cross }}+\varphi_{\text {max }}^{\text {cross }} \cdot \exp \left(-K^{\text {cross }} \cdot p^{\Sigma \Sigma}\right) \\
\operatorname{stab}\left(\delta^{\mathrm{CTRL}}\right)=\varphi_{\max }^{\text {stab }} \cdot \tanh \left(K^{\text {stab }} \cdot \delta^{\mathrm{CTRL}}\right)
\end{gathered}
$$

Where: $\delta_{\min }^{\text {border }}$ и $\delta_{\text {max }}$ border - minimal and maximal border size of the search zone; $K^{\text {border }}$

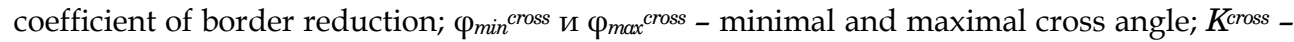
coefficient of the cross angle reduction; $\varphi_{\text {max }}{ }^{\text {stab }}$ - maximal angle of mutual AUV-to-object offset compensation; $K^{\text {stab }}$ - AUV trajectory stabilization coefficient at movement lengthways the inspection object.

AUV control system calculates object survey zone and control heading. Thus, the trajectory of underwater vehicle will represent oscillatory movement along the inspection object (fig. 
$6,13)$. The amplitude of fluctuations is inversely to the object existence probability near the AUV. The maximal estimation of the probability changes movement to a direct line. When estimation is reduced (loss of the object) the oscillatory movements appear again.

\section{Modeling experiments and sea trial results}

The proposed approach consistency was proved by means of modeling experiments (for the ESS-data using) and by sea trials (for jointly using of VIC and EMS-data).

\subsection{Modeling experiments of pipeline inspection}

Investigation of AUV behavior during inspection of pipeline, which is partly filled up with ground, was carried out by means of modeling. The modeling environment includes:

- 3D-model of bottom surface and artificial objects (pipeline in this case);

- AUV dynamic and kinematics models;

- $\quad$ echo-sounder model.

The model of bottom surface (fig. 9) along with model of artificial objects allows to form any terrain shapes, including concave and ambiguous (Pavin, 2005). The model includes three basic levels of detailed elaboration. The micro level corresponds to accuracy of the echo sounder (centimeters). The middle level corresponds to AUV motion during updating the data (decimeters). The macro level describes the general bottom characteristics. The model allows to set characteristics for each of three levels. For more careful test of identification algorithms the terrain model has been added with an opportunity of generation: "visor" and "stone". The macro-relief is used as a skeleton on which middle- and micro-levels are placed according to the certain rules.

The echo sounder model is applicable for calculation as single beam (with the fixed diagram of an orientation), and multi-beam echo-sounders. Thus, the basic characteristics of the echo sounder are taken into account: their layout onboard the AUV and the sensor direction, range and precision of measurements, directional diagram.

The echo sounder was modeled by several acoustic beams (from 5 up to 20) directed fanshaped downwards in sector of $40^{\circ}$. AUV mission consisted of detection of the pipeline, motion along it, pipeline sagging detection and its contouring. Many variants of terrain, pipeline position and various number of echo sounder beams were modeled.

In fig. 9-11 the results of partly buried pipeline detection are demonstrated. The pipeline diameter is $1.6 \mathrm{~m}$. The level of pipeline hiding in sea bottom is $50 \%$ (on average). The number of used echo sounder beams - 10. Motion altitude is $3 \mathrm{~m}$. Motion speed is about 0.8 $\mathrm{m} / \mathrm{s}$ and depends on echo sounder data update rate.

Scheme of modeling experiment is presented on fig. 9. Terrain "coverage" by echo sounders is represented by blue strip of variable width along the AUV lane (left picture). Right picture illustrates 3D-view of the main inspection phase. It includes freespan detection and survey. AUV has moved along the pipeline, found out sagging, contoured it and renewed motion further along the pipeline. In fig. 10 echo sounder data of AUV portside and starboard are shown (5 sonar beams from each side). The figure presents results of automatic sagging detection on the base of these data. In fig. 11 the probability of pipeline presence in echo sounder field of vision is illustrated. It is supposed that pipeline "exists" if this value is positive. In this case AUV offset is calculated (blue points on the graph) and used in control. 


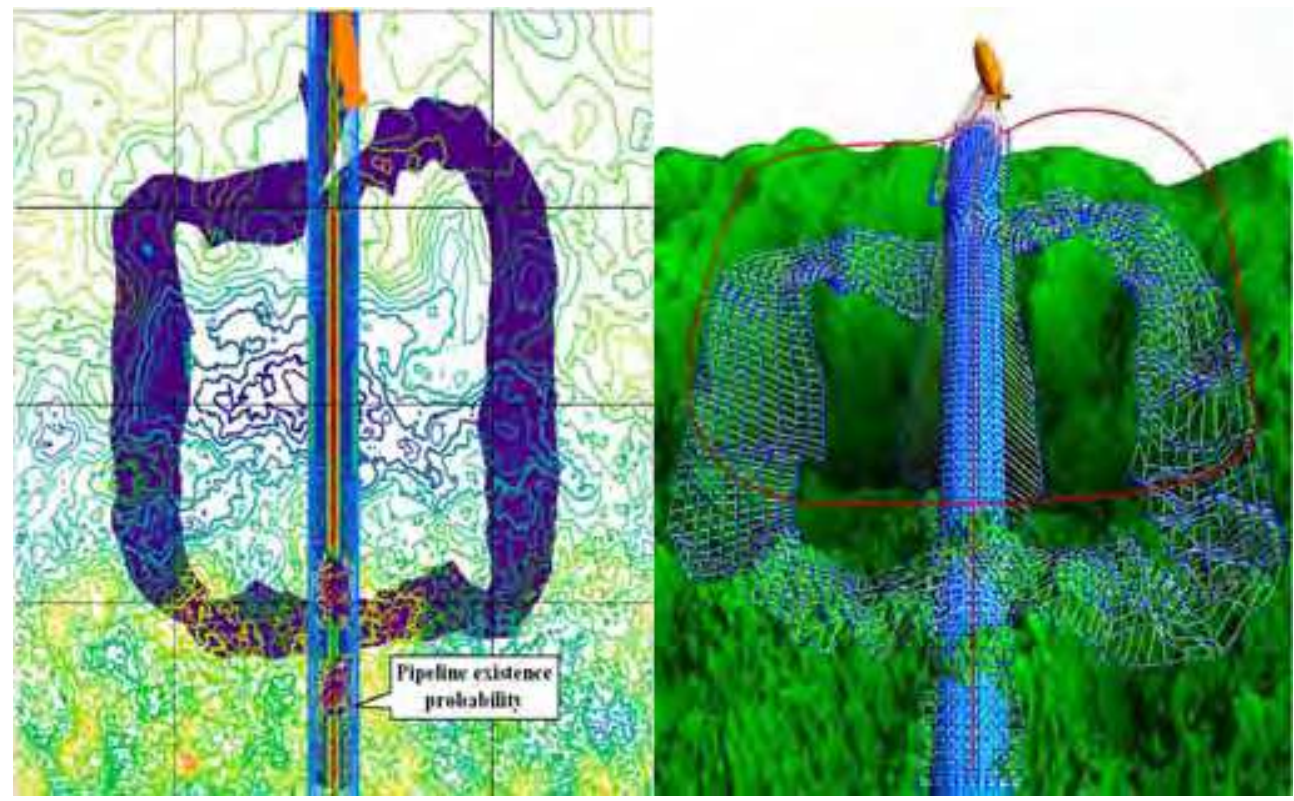

Fig. 9. Pipeline detection (left picture) and 3D-view of pipeline inspection (right picture)

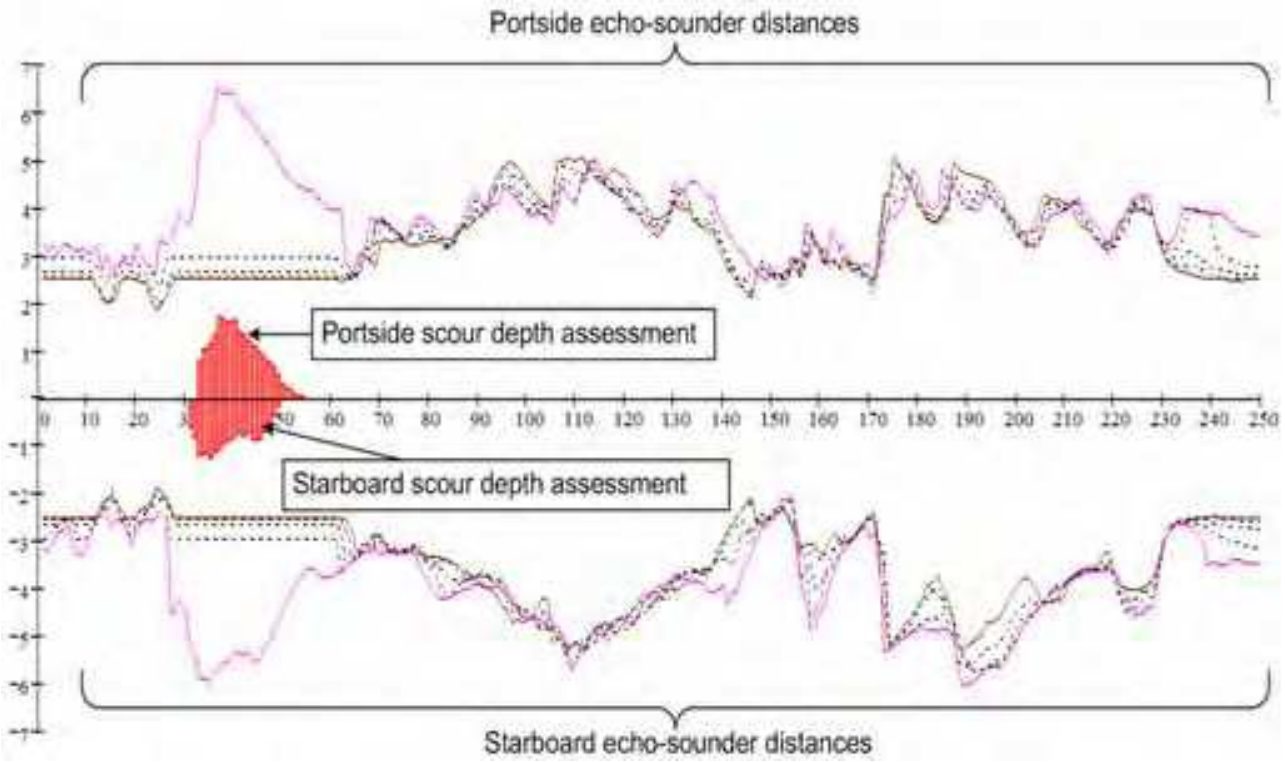

Fig. 10. Echo sounder data and pipeline freespan assessment during sagging inspection 


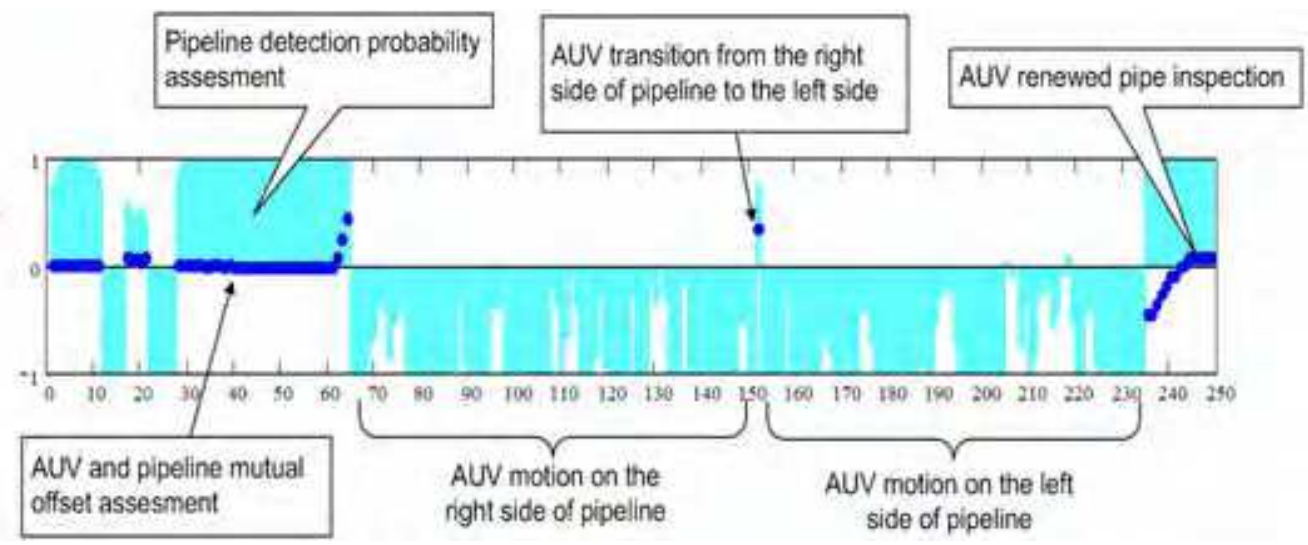

Fig. 11. Pipeline detection probability and mutual offset assessment

\subsection{Sea trial results of cable inspection}

The first full-scale experiments were made with the use of VIC and EMS developed in the Institute of Marine Technology Problems. Both devices were installed aboard AUV MT-98 (Fig. 12) and used for automatic inspection of thin metallic cable, which was preliminary laid on the bay floor.

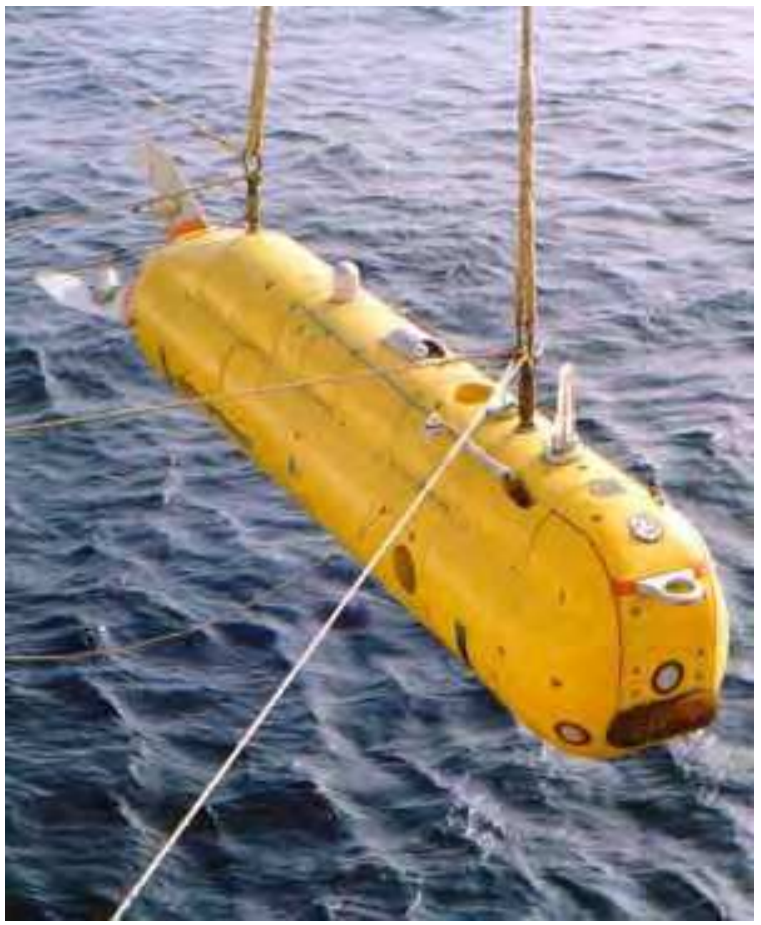

Fig. 12. AUV MT-98 
The described method was realized in a coordinating level of AUV control system. AUV sea trials were carried out in two stages (fig. 13):

1. EMS only was involved as a cable recognition system,

2. EMS and VIC were used for cable detection simultaneously.

Sea trial parameters and some results are summarized in table 1.

\begin{tabular}{|l|c|}
\hline \multicolumn{1}{|c|}{ Parameter } & Value \\
\hline Cable diameter & $12 \mathrm{~mm}$ \\
\hline Cable length & $800 \mathrm{~m}$ \\
\hline Approx cable direction & $180^{\circ}$ \\
\hline Average AUV altitude & $1.7 \mathrm{~m}$ \\
\hline Average AUV velocity & $0.35 \mathrm{~m} / \mathrm{s}$ \\
\hline Average inspection speed (EMS only detection using) & $0.2 \mathrm{~m} / \mathrm{s}$ \\
\hline Average inspection speed (EMS \& VIC detection using) & $0.3 \mathrm{~m} / \mathrm{s}$ \\
\hline AUV-cable offset dispersion (EMS only detection using) & $1.5 \mathrm{~m}$ \\
\hline AUV-cable offset dispersion (EMS \& VIC detection using) & $0.5 \mathrm{~m}$ \\
\hline Maximal AUV-cable offset (EMS only detection using) & $3 \mathrm{~m}$ \\
\hline Maximal AUV-cable offset (EMS \& VIC detection using) & $1.5 \mathrm{~m}$ \\
\hline Cable presence on photo images (EMS only detection using) & $30 \%$ \\
\hline Cable presence on photo images (EMS \& VIC detection using) & $90 \%$ \\
\hline
\end{tabular}

Table 1. Field Test Parameters and Results

In both cases after first EMS-contact underwater vehicle made "zigzag" movement along a general cable direction to collect the contact statistic. As four minutes passed (from the first EMS contact) AUV started search movements guided by inspection zone borders. In the result all test part of the cable was inspected by AUV in autonomous mode (fig. 13, 14-left picture).

The second full-scale experiment was carried out during the inspection of real cable, which has been laid several years ago on bottom of Ussuriysky Bay of Japan Sea. The cable is partly silted and also surrounded by sea organisms (fig. 14 central pictures).

AUV moved above silted cable fragments by "zigzag" and straight forward along well seen sites of cable. The total length of the surveyed fragment of the cable composed $13 \mathrm{~km}$. The scheme of inspection consisted of two stages. At the first stage the AUV moved at height of $1.7 \mathrm{~m}$ with the use of EMS \& VIC, specified cable position and carried out its photographing. The control system registered coordinates of intersection points with the cable. At the second stage the AUV rose on height of $5 \mathrm{~m}$, departed aside from the cable approximately on 20-25 m and came back along the cable in an initial point (registered coordinates were used). At the same time HF SSS (fig. 14 right picture) survey of cable vicinities was being carried out (i.e. the motion was similar to inspection of pipeline freespan). 

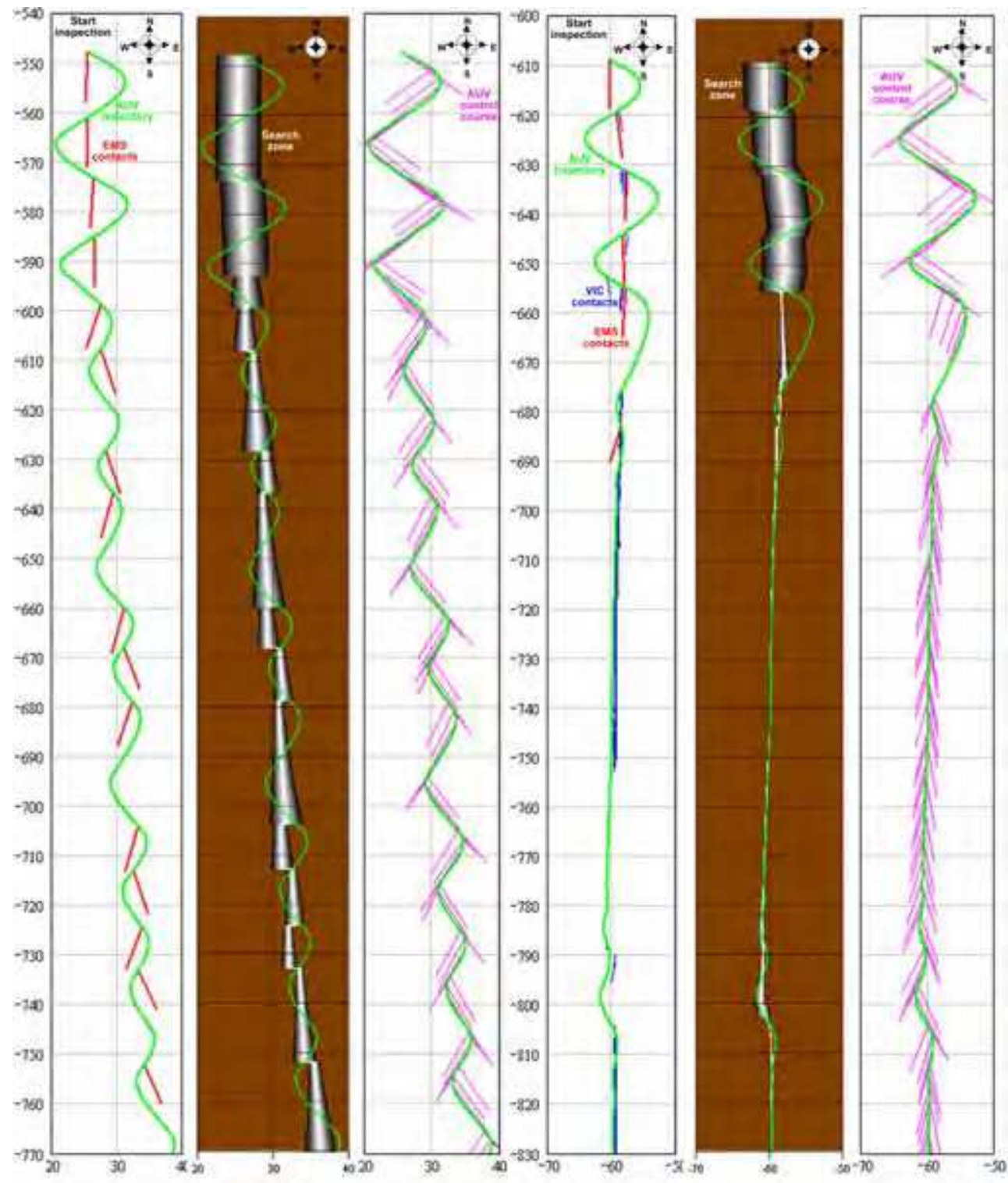

Fig. 13. AUV cable inspection with using of EMS only (left) and using EMS \& VIC (right) 


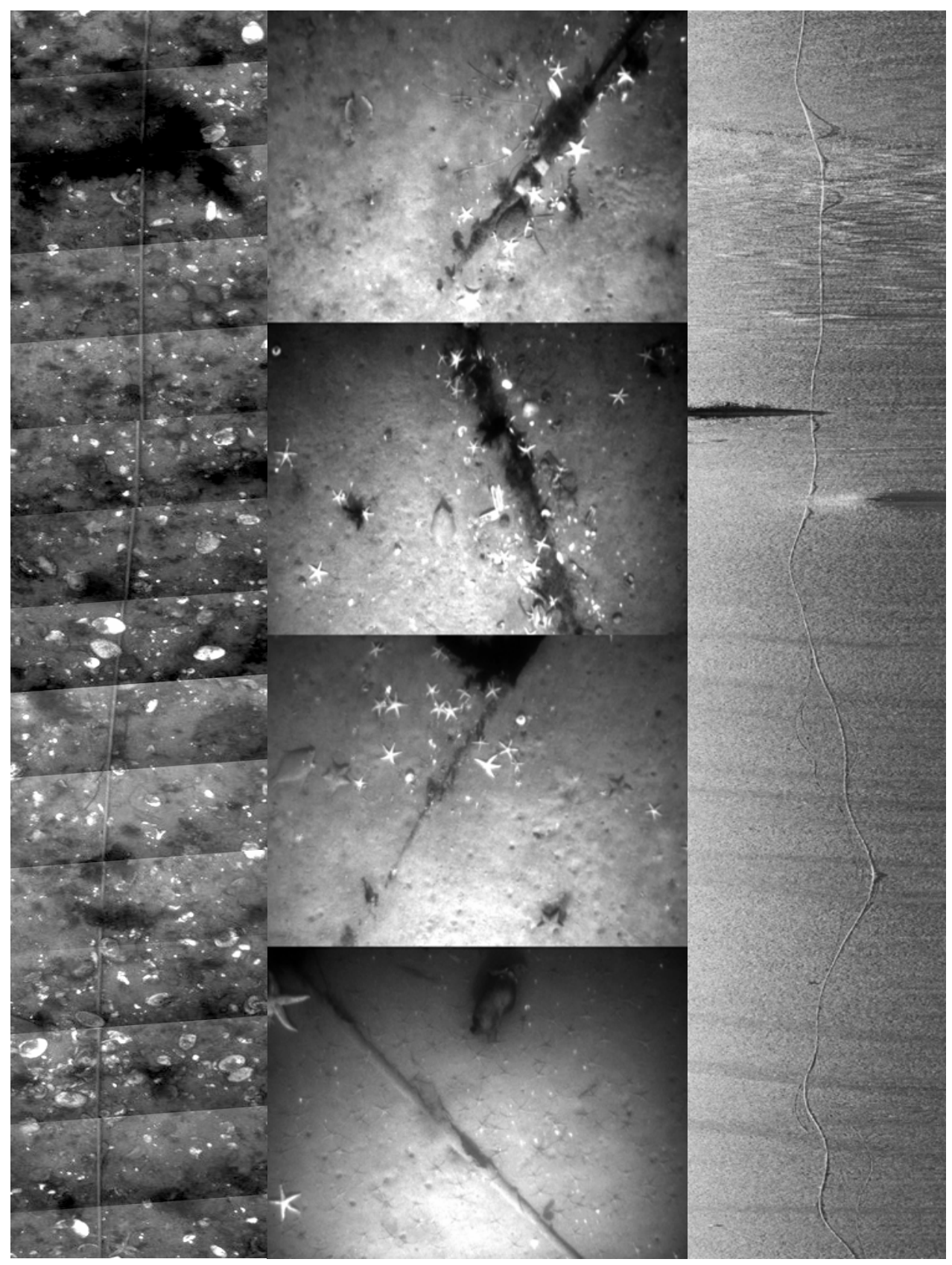

Fig. 14. Photo-images sequences during AUV movement along a cable (left picture), photoimages (central pictures) and HF-SSS image (right picture) of partly visible cable 


\section{Conclusion}

Described method of data calculation and AUV control model are used in underwater vehicles designed in Institute of Marine Technology Problems. Sea trial results confirmed high performance of the VIC \& EMS integration method. The modeling results of ESS allow to appreciate optimistically an opportunity of the algorithm using for solving of pipeline inspection problems. The method has shown the serviceability and to a first approximation it is supposed to use in the control system of existing AUV for detection and the motion organization along the acoustically visible lengthy cylindrical objects (in particular, pipelines). However the method requires testing with use of real ESS and the pipeline.

Future method development consists of data integration from low frequency \& high frequency SSS for pipeline and cable tracking. Experiments with the use of Hough transformation for detection of lengthy objects on SSS-images yield encouraging results.

Authors thank IMTP directions for R\&D support and colleagues - for the help in carrying out of sea tests.

\section{References}

Ageev, M. (2005). AUV Equipment and Control While Conducting Investigation of Underwater Pipeline (in Russian), Underwater Technologies, №1, pp. 68-72, Dalnauka, Vladivostok, Russia

Asai, T.; Kojima, J.; Asakawa, K. \& Iso, T. (2000). Inspection of submarine cable of over 400 $\mathrm{km}$ by AUV, Proceedings of the 2000 International Symposium on Underwater Technology, UT 00, pp. 133 - 135, May 2000, Tokyo, Japan

Baker, J. (1991). Alternative Approaches to Pipeline Survey. Subtech'91, Vol. 27, pp. 333-345.

Evans, J.; Petillot, Y.; Redmond, P.; Wilson, M. \& Lane, D. (2003). AUTOTRACKER: RealTime Architecture for Pipeline and Cable Tracking on AUVs, Proceedings of 13th International Symposium On Unmanned Untethered Submersible Technology (UUST03)

Inzartsev, A. \& Pavin, A. (2006). AUV Behavior Algorithm While Inspecting of Partly Visible Pipeline, Proceedings of the OCEANS 2006 MTS/IEEE Conference, ISBN 1-4244-0115-1, September 2006, Boston, MA, USA

Inzartsev, A. \& Pavin, A. (2008). AUV Cable Tracking System Based on Electromagnetic and Video Data, Proceedings of OCEANS'08 MTS/IEEE Kobe-Techno-Ocean'08 (OTO'08), ISBN: 978-1-4244-2126-8, April 2008, Kobe, Japan

Kogan, I.; Paull, C. at al. (2006). ATOC/Pioneer Seamount cable after 8 years on the seafloor: Observations, environmental impact, Continental Shelf Research, Volume 26, Issue 6, April 2006, pp. 771-787

Kojima, J.; Ito, Y.; Asakawa, K. et al. (1997). Development of Autonomous Underwater Vehicle "Aqua Exporer 2" for Inspection of Underwater Cables. Proc. of MTS/IEEE, Oceans'97, Canada

Kukarskih, A. \& Pavin, A. (2008). Using of Electromagnetic Searcher for Inspection of Metallic Cable by Means of AUV, Proceedings of OCEANS'08 MTS/IEEE KobeTechno-Ocean'08 (OTO’08), ISBN: 978-1-4244-2126-8, April 2008, Kobe, Japan

Matsumoto, S. \& Ito, Y. (1995), Real-Time Vision-Based Tracking of Submarine-Cables for AUV/ROV, Proc. of Conf. Oceans'95

Murray, B. (1991). Pipeline Freespan Monitoring. Subtech'91, Vol. 27, pp. 347-354 
Ortiz, A.; Simó, M. \& Oliver, G. (2000). Image Sequence Analysis for Real-Time Underwater Cable Tracking, Fifth IEEE Workshop on Applications of Computer Vision (WACV'00), p. 230

Pavin, A. (2005). Simulation Environment for AUV Control Algorithms Development, Proceedings of 14th International Symposium on Unmanned Untethered Submersible Technology, August 2005, Durham, New Hampshire, USA

Pavin, A. (2006). The Pipeline Identification Method Basing on AUV's Echo-Sounder Data, Proceedings of the OCEANS 2006 MTS/IEEE Conference, ISBN 1-4244-0115-1, September 2006, Boston, MA USA

Petillot, Y.; Reed, S. \& Bell, J. (2002). Real time AUV pipeline detection and tracking using side scan sonar and multi-beam echosounder, Oceans '02 MTS/IEEE, Volume: 1, pp. 217-222, October 2002

Scherbatyuk, A. (1998). Comparison of Methods for Identifying Objects with Rectilinear Edges on Underwater Video Images. Pattern Recognition and Image Analysis, Vol. 8, № 3, 1998, pp. 467 - 469

Scherbatyuk, A.; Boreyko, A. \& Vaulin, Yu. (2000). AUV Operation Based on Video Data Processing: Some IMTP Experience, Workshop on Sensors and Sensing Technology for Autonomous Ocean Systems, Oct -Nov 2000, Hawaii 


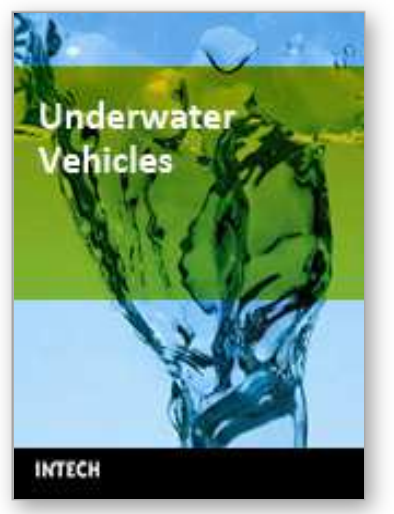

\author{
Underwater Vehicles \\ Edited by Alexander V. Inzartsev
}

ISBN 978-953-7619-49-7

Hard cover, 582 pages

Publisher InTech

Published online 01, January, 2009

Published in print edition January, 2009

For the latest twenty to thirty years, a significant number of AUVs has been created for the solving of wide spectrum of scientific and applied tasks of ocean development and research. For the short time period the AUVs have shown the efficiency at performance of complex search and inspection works and opened a number of new important applications. Initially the information about AUVs had mainly review-advertising character but now more attention is paid to practical achievements, problems and systems technologies. AUVs are losing their prototype status and have become a fully operational, reliable and effective tool and modern multi-purpose AUVs represent the new class of underwater robotic objects with inherent tasks and practical applications, particular features of technology, systems structure and functional properties.

\title{
How to reference
}

In order to correctly reference this scholarly work, feel free to copy and paste the following:

Alexander Inzartsev and Alexander Pavin (2009). AUV Application for Inspection of Underwater Communications, Underwater Vehicles, Alexander V. Inzartsev (Ed.), ISBN: 978-953-7619-49-7, InTech, Available from:

http://www.intechopen.com/books/underwater_vehicles/auv_application_for_inspection_of_underwater_comm unications

\section{INTECH}

open science | open minds

\author{
InTech Europe \\ University Campus STeP Ri \\ Slavka Krautzeka 83/A \\ 51000 Rijeka, Croatia \\ Phone: +385 (51) 770447 \\ Fax: +385 (51) 686166 \\ www.intechopen.com
}

\author{
InTech China \\ Unit 405, Office Block, Hotel Equatorial Shanghai \\ No.65, Yan An Road (West), Shanghai, 200040, China \\ 中国上海市延安西路65号上海国际贵都大饭店办公楼405单元 \\ Phone: +86-21-62489820 \\ Fax: $+86-21-62489821$
}


(C) 2009 The Author(s). Licensee IntechOpen. This chapter is distributed under the terms of the Creative Commons Attribution-NonCommercialShareAlike-3.0 License, which permits use, distribution and reproduction for non-commercial purposes, provided the original is properly cited and derivative works building on this content are distributed under the same license. 